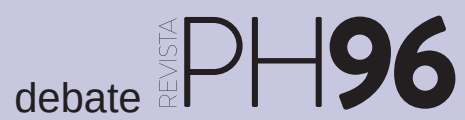

a debate Memoria democrática en la construcción de la historia y el patrimonio

| coordina Josefina Cuesta Bustillo

\title{
La memoria histórica y su dimensión política, social y académica
}

Custodio Velasco Mesa | Dpto. de Historia Contemporánea, Universidad de Sevilla

URL de la contribución <www.iaph.es/revistaph/index.php/revistaph/article/view/4302>

En el debate internacional acerca de la memoria histórica cabe distinguir tres grandes vertientes convergentes que implican a distintos actores sociales y que es importante identificar, no solo para comprender las tensiones y conflictos generados al respecto, sino también para intentar hallar vías que los resuelvan desde premisas democráticas.

Las polémicas remiten, en lo inmediato, a la estructural dimensión política inherente a la historia y, por derivación, a toda tentativa de poner de relieve un discurso contrahegemónico de la historia, es decir: remiten a los efectos que la emergencia de toda memoria silenciada tiene en la deconstrucción de relatos hegemónicos acerca del pasado. Relatos que, en particular desde el siglo XIX (cuando la opinión pública empezó a cobrar trascendencia política), han sido habitualmente utilizados como instrumentos privilegiados de propaganda al servicio del poder establecido, esto es: como herramientas para crear identidades colectivas, para generar adhesiones y cohesiones en torno a ese poder, para legitimar o facilitar -en suma- el ejercicio de la autoridad. En realidad, toda comunidad que ha adquirido algún grado de organización social ha desarrollado también algún tipo de narrativa y de política (educativa, de símbolos -materiales e inmateriales- o de concienciación) en relación con su pasado (CLOSA MONTERO, 2010: 3); y ello con independencia del tipo de régimen político adoptado. En ese proceder, a mayor grado de represión ejercida por la autoridad política, mayor ha sido la imposición de discursos hegemónicos o políticas memoriales que ensalzan los valores que representa el poder establecido, al tiempo que más elevada es la omisión o tergiversación de hechos y narrativas que contradicen esa propaganda. A la inversa, a mayor calidad democrática del régimen, mayor es la emergencia de memorias contra-hegemóni- cas, frecuentemente presentadas como una modalidad de la discusión y del conflicto político.

En todo caso, cabe destacar que, tanto en los contextos represivos como en los democráticos, la autoridad política, pese a su grado de control sobre los instrumentos de difusión de recuerdos, sobre leyes de memoria o sobre conmemoraciones oficiales, no tiene el monopolio de la memoria, como tampoco es su única depositaria. De ahí, precisamente, el conflicto al respecto, latente en periodos represivos, explícito en periodos democráticos. Los debates y tensiones en torno a la memoria son, en este sentido, síntomas de la gradual evolución que, desde finales del siglo $\mathrm{XX}$, experimenta la ciudadanía hacia una mayor expresión en el espacio público y, en consecuencia, hacia una mayor participación política dentro de las democracias incompletas de las sociedades complejas contemporáneas. Teniendo ello presente, no sorprende el alcance internacional que en los últimos años ha adquirido el conflicto entre memorias hegemónicas y contrahegemónicas. De hecho, difícilmente puede encontrarse en la actualidad un país que no experimente disputas ligadas a su(s) memoria(s) de traumas colectivos. Destacan los casos de Europa Central y del Este con relación al estalinismo, los de América Latina en relación con sus dictaduras y conflictos armados, el de Turquía (genocidio armenio de 1915) o el de Francia en lo que respecta al colaboracionismo nazi y a su pasado colonial; casos, todos ellos, donde se advierten tensiones o "guerras de memoria" con trascendencia en la construcción de identidades colectivas".

Junto a la estructural dimensión política, las polémicas acerca de la memoria tienen, asimismo, una inmediata y elemental dimensión humana y social, por cuanto afectan, en el presente, a sentimientos íntimos de víctimas, 
a debate Memoria democrática en la construcción de la historia y el patrimonio

| coordina Josefina Cuesta Bustillo

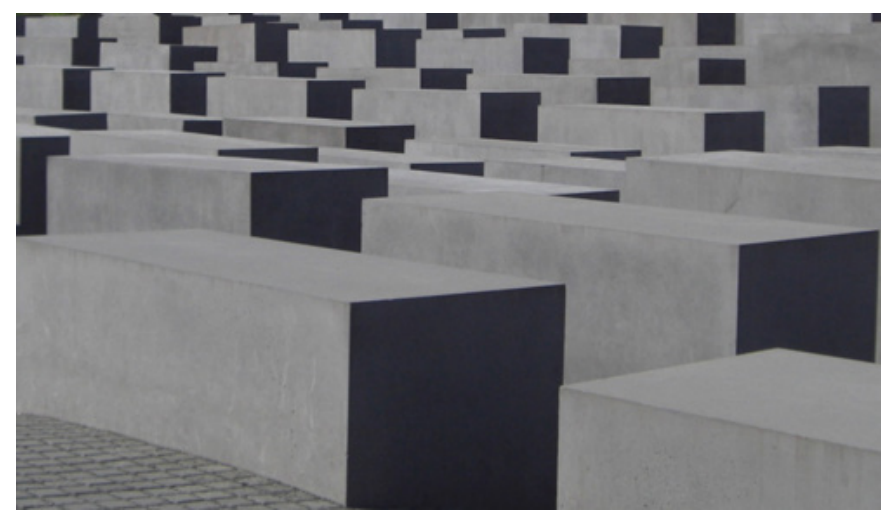

Memorial del Holocausto, Peter Eisenman, Berlín, 2005 | foto Custodio Velasco

que se han organizado para llevar a cabo sus reclamaciones. A decir verdad, la toma en consideración de la memoria constituye, en su origen, la reivindicación de individuos y colectivos que, desde finales del siglo $X X$, vienen solicitando justicia, reparación y verdad en relación con violencias colectivas silenciadas o tergiversadas por las narrativas hegemónicas en distintos contextos internacionales. Fueron, efectivamente, víctimas y familiares de éstas quienes, espontánea y autónomamente, emprendieron la creación de asociaciones mediante las que articularon sus demandas individuales y colectivas, interpelando con ello -directa o indirectamente- a distintos profesionales involucrados al respecto (BARROS, 2014: 154). Por una parte, apelaron a políticos y a jueces, teniendo como referentes los Juicios de Nüremberg de 1945 a los responsables del Holocausto. Como en otro lugar he destacado, el reconocimiento y tipificación en la ONU de crímenes de lesa humanidad (no susceptibles de ser amnistiados e imprescriptibles, a diferencia de los crímenes de guerra) y el posterior despliegue de legislaciones nacionales que penalizaban en distintos países el negacionismo del Holocausto, supusieron un poderoso estímulo para que diferentes movimientos memorialistas reclamaran para sí la consideración de víctimas de crímenes de lesa humanidad y el consiguiente reconocimiento -en materia de políticas de memoriapor parte de las administraciones públicas (VELASCO MESA, 2017: 127-128). Por otra parte, junto a políticos y a jueces, estas asociaciones también habrían de apelar a historiadores para que éstos -en su labor de esclareci- miento de la historia- tuvieran en consideración los testimonios de las víctimas, colaboraran en la localización de fosas comunes, contribuyeran, en suma, mediante sus investigaciones, a poner de relieve acontecimientos silenciados o tergiversados que permitieran precisar y reinterpretar relatos hegemónicos del pasado.

Con independencia, sin embargo, de esa interpelación directa o indirecta a profesionales de la historia, es obvio que las controversias acerca de la memoria incumben decididamente a los historiadores. De hecho, afectan a la propia epistemología de la historia y, en esa medida, tienen, junto a la política y a la social, una inequívoca dimensión académica. A este respecto, se distinguen dos posturas antagónicas. De un lado, la que considera que la memoria no es asunto de la historia ni, por consiguiente, de la atención del historiador ${ }^{2}$. De otro, la que reivindica lo contrario: la integración de la memoria en la historia y su consideración como fuente para el conocimiento del pasado ${ }^{3}$. A este último grupo se adscriben quienes consideran que el historiador, por elemental deontología profesional, no puede, en su tentativa de aproximación a la verdad histórica, desestimar o subestimar ninguna fuente de conocimiento del pasado, incluyendo los testimonios de las víctimas de tragedias colectivas, que son en ocasiones la única fuente existente en contextos represivos. Antes bien, debe incorporar -contrastándolos- esos testimonios a su labor de esclarecimiento y análisis de acontecimientos históricos. Conforme a ello, desde esta perspectiva la utilidad de la historia no se reduce a una utilidad científica, no se limita al conocimiento -lo más exhaustivo posible- del pasado, no consiste en un conocimiento, sin más, de ese pasado, sino en un conocimiento (lo más riguroso posible) y una reflexión sobre los hechos que, particularmente en el caso que nos ocupa, contribuyan a evitar la reedición de horrores colectivos. Y ello pasa, no ya por poner en evidencia esas tragedias, sino también por no exaltar, mediante distintas modalidades discursivas o comunicativas, los valores que las propiciaron.

Dicho esto, en el abigarrado debate acerca de la memoria, donde se mezclan sentimientos íntimos de víctimas 
(y sus reivindicaciones) con vertientes políticas y epistemológicas de la historia, cabe destacar que lo decisivo no es exactamente el acto de "propagar", bien mediante políticas con relación al pasado (incluyendo leyes sobre memoria, símbolos y conmemoraciones), bien mediante plataformas diversas de comunicación (prensa y medios audiovisuales), bien a través del estricto análisis de la historia. Ese acto de "propagar" es, se quiera o no, inevitable para todos los actores sociales partícipes en el debate. Lo decisivo es determinar qué es lo que se propaga, es decir: si lo que se propaga consigue o no transmitir y "desentrañar el significado de una experiencia" (MATE, 2018), si tiene (es) o no base documental y si se pone o no al servicio del conocimiento de los hechos, de la justicia y del respeto a los derechos humanos, también en el presente pues la memoria no trata únicamente del pasado (VELASCO MESA, 2017: 135), sin "disneyficaciones" que banalicen el recuerdo de las tragedias, sin sacralizaciones o mitificaciones, sin estériles competiciones en la escala del horror (TODOROV, 1994: 272), desde el respeto a la vida de todo ser humano.

De la respuesta que demos a esas cuestiones dependen no ya los avances en el conocimiento científico de la historia, sino también la superación de traumas colectivos y los progresos en la convivencia ciudadana. La Unión Europea parece haber comprendido la trascendencia del problema si se tiene en cuenta la promoción que viene realizando desde 2004 en favor del conocimiento de las memorias silenciadas de diferentes pasados traumáticos en Europa; y ello, mediante dos programas: "Europe for Citizens Programme" (2007-2013) y "Uses of the Past" (2014-2020). No en vano, en el espacio europeo han tenido lugar en los últimos siglos dos grandes trayectorias ideológicas contrapuestas que constituyen la médula de lo que se discute cuando se discute sobre la memoria. Por una parte, con particular énfasis desde fines del siglo XIX, se ha desarrollado una "cultura de la guerra" o de la violencia que, integrada en una "política de las emociones", desembocó en los totalitarismos del siglo $X X$, ahora reeditados en los (ultra)nacionalismos y filofascismos del XXI. No obstante, paralelamente a esa "cultura de la guerra", Europa también ha sido el suelo de una "cultura de la paz" que remite a los valores de la tolerancia y del consenso difundidos desde el racionalismo del siglo XVIII y sobre la que es necesario insistir como antemural frente a los totalitarismos y como referente fundamental para construir la convivencia democrática, imposible de articular plenamente sin el conocimiento y el reconocimiento de las tragedias colectivas silenciadas.

\section{NOTAS}

1. Sobre el caso de los países de Europa del Este en relación con la memoria de la dominación soviética, véase Closa Montero (2010: 11-19). En lo que respecta a la Europa occidental, los conflictos en torno a la memoria están experimentando una notable evolución desde que, entre 1945 y 1967, se viviera lo que J.-M. Chaumont denomina "tiempo de la vergüenza", caracterizado por focalizar el recuerdo en honrar a la Resistencia sin mención al Holocausto, y en los años setenta se advirtiera lo contrario: la glorificación de los rescatados del Holocausto (CHAUMONT, 1997; GENSBURGER; LAVABRE, 2005: 80). En ello coinciden Eva-Clarita Onken y Emmanuelle Droit, quienes consideran que tras 1945 se instala en países como Francia, Bélgica o Italia el mito de la Resistencia nacional; un consenso que, desde los años setenta, se empezará a fracturar, al tiempo que la memoria del Holocausto superaba el marco restringido de las comunidades judías (ONKEN, 2007: 31; DROIT, 2007: 103-104).

No obstante, esa memoria del Holocausto no entrará plenamente en la memoria oficial de países como Francia hasta los años 1990, integrando un más amplio movimiento que empezó a fijar desde los años ochenta la centralidad del Holocausto en la identidad y la memoria de la Europa occidental (JUDT, 2005: 820). Con todo, Francia ha evolucionado en las últimas décadas del régimen memorialista orientado a la exaltación de los héroes de la Resistencia a lo que J. Michel ha denominado "régimen victimo-memorialista", basado en una concepción 


\section{a debate Memoria democrática en la construcción de la historia y el patrimonio \\ | coordina Josefina Cuesta Bustillo}

plural de la memoria y en la noción de crimen contra la humanidad como fuente jurídica (MICHEL, 2010: 84 y ss.).

2. Exponente de ello es Pierre Nora, para quien memoria e historia, "lejos de ser sinónimos, se oponen completamente entre sí" (NORA, 1984: 19; 1978: 398-401).

3. Es la postura que defienden, entre otros, Carlos Barros, quien sostiene la integración de la memoria en la historia, al tiempo que concibe la historia con una esencial dimensión humana, hecha por historiadores, pero también por "los protagonistas actuales a través de su memoria colectiva (BARROS, 2011, 5 de diciembre).

\section{BIBLIOGRAFÍA}

- BARROS, C. (2011) Historia de la memoria, memoria de la historia [en línea] Conferencia impartida en la Escuela Nacional de Antropología e Historia, México D.F., México, 5 de diciembre de 2011 <https://www.youtube.com/watch?v=euRNzJOHMcl> [Consulta: 20/11/2018]

- BARRos, C. (2014) Historia, memoria y franquismo. Historia Actual Online, n. ${ }^{\circ} 33,2014$, pp. 153-171

- CHAUMONT, J-M. (1997) La concurrence des victimes, génocide, identité, reconnaissance. París: La Découverte, 1997

- ClOSA MONTERO, C. (2010) Negociating the Past: Claims for Recognition and Policies of Memory in the EU [disponible en línea]. Madrid: Consejo Superior de Investigaciones Científicas (España), 2010 (Serie Documentos de trabajo, n. ${ }^{\circ}$ 8, Instituto de Políticas y Bienes Públicos -IPP-). <http://hdl. handle.net/10261/24430> [Consulta: 14/11/2018]

- DROIT, E. (2007) Le Goulag contre la Shoah. Mémoires officielles et cultures mémorielles dans l'Europe élargie. Vingtième Siècle. Revue d'histoire, n. ${ }^{0}$ 94, 2007, pp. 101-120

- GENSBURGER, S.; LAVABRE, M-C. (2005) Entre devoir de mémoire et abus de mémoire: la sociologie de la mémoire comme tierce position. En MÜLLER, B. (2005) Histoire, mémoire et épistemologie. A propos de Paul Ricoeur. Lausanne: Payot, 2005, pp. 76-95

- JUDT, T. (2005) Postwar. A History of Europe since 1945. New York: The Penguin Press, 2005
- MATE, R. (2018) [Declaraciones publicadas en el artículo de GALINDO, J. C. ¿Se puede mentir en una novela sobre el Holocausto?, El País [en línea] 24/11/2018<https://elpais. com/cultura/2018/11/23/actualidad/1542966934_093230. html> [Consulta: 25/11/2018]

- MICHEL, J. (2010) Gouverner les mémoires, Les politiques mémorielles en France. París: PUF, 2005

- NORA, P. (1978) Mémoire collective. En LE GOFF, J.; CHARTIER, R.; REVEL, J. (dir.) La nouvelle histoire. París: Retz-CEPL, 1984

- NORA, P. (1984) Entre mémoire et histoire. En NORA, P. (dir.) Les lieux de la mémoire. La République. París: Gallimard, 1984

- ONKEN, E.-C. (2007) The Baltic States and Moscow's 9 May commemoration: analysing memory politics. Europe EuropeAsia Studies, vol. 59, n. ${ }^{\circ}$ 1, 2007, pp. 23-46

- TOdOROV, T. (1994) Face à l'extrême. París: Seuil, 1994

- VELASCO MESA, C. (2017) Historia y memoria: un mismo combate. Aportaciones epistemológicas de Historia a Debate a las controversias acerca de la memoria histórica. Memorias: Revista Digital de Arqueología e Historia desde el Caribe, n. ${ }^{\circ}$ 33, septiembre-diciembre 2017, pp. 120-141 